\title{
Nutrientes na solução do solo em floresta de terra firme na Amazônia Central submetida à extração seletiva de madeira ${ }^{1}$
}

\author{
Sávio J. Filgueiras FERREIRA², Flávio J. LUIZÃO ${ }^{3}$, Sebastião Átila F. MIRANDA², Maria do Socorro R. da
} SILVA $^{2}$, Ana Rosa Tundis VITAL ${ }^{2}$

\begin{abstract}
RESUMO
Os solos de terra firme da Amazônia Central, na sua maioria, são ácidos, pobres em nutrientes e a manutenção da floresta sobre esses solos é garantida pela ciclagem de nutrientes, praticamente fechada. A substituição de floresta por pastagens ou outras atividades agrícolas leva à diminuição de nutrientes do compartimento biomassa, podendo comprometer os processos de ciclagem no solo, pois plantas absorvem nutrientes que presentes na solução do solo. Para entender o efeito de retirada de árvores, foi realizado um estudo em uma área de floresta de terra firme na Amazônia Central submetida à extração seletiva de madeira (6-10 árvores, ou $34 \mathrm{~m}^{3} \mathrm{ha}^{-1}$ de madeira) localizada $80 \mathrm{~km}$ ao norte de Manaus, foram determinados os teores $\mathrm{NO}_{3}$; $\mathrm{NH}_{4}^{+}, \mathrm{K}^{+}, \mathrm{Ca}^{2+}, \mathrm{Mg}^{2+}$ e Na ${ }^{+}$na solução do solo na camada de 0-30 cm. O experimento constou de três blocos, cada um contendo uma parcela controle e uma que sofreu o corte seletivo de árvores, todos sobre um Latossolo Amarelo álico de textura muito argilosa. As medidas foram realizadas durante 13 meses, em cinco tratamentos em cada bloco: controle (floresta intacta), centro de clareira, borda de clareira, borda da floresta remanescente e floresta remanescente. Os teores de potássio, cálcio, magnésio e sódio mostraram diferenças significativas entre os tratamentos. As quantidades dos íons amônio e nitrato foram as menos afetadas. Os valores mais elevados foram geralmente encontrados nos tratamentos centro de clareira e borda de clareira. A maior diferença ocorreu na quantidade de sódio na solução do solo, que chegou a mais de $5 \mathrm{~kg} \mathrm{ha}^{-1}$, no centro de clareira de dois blocos, praticamente o dobro da encontrada nas suas respectivas parcelas controles. As concentrações mais baixas dos nutrientes na solução do solo da floresta intacta (controle) e da floresta remanescente, confirmam a eficiência da floresta na ciclagem de nutrientes. Porém, no centro de clareira, além da remoção de árvores, a disponibilidade de materiais de fácil decomposição, como raízes mortas e a liteira acumulada, podem ter contribuído para uma maior concentração de nutrientes na solução do solo.
\end{abstract}

PALAVRAS-CHAVE

Manejo florestal, ciclagem de nutrientes, ecossistema florestal, Amazônia central.

\section{Nutrients in soil solution in an upland forest submitted to selective logging in central Amazonia}

\begin{abstract}
The nutrients $\mathrm{NO}_{3}, \mathrm{NH}_{4}^{+}, \mathrm{K}^{+}, \mathrm{Ca}^{2+}, \mathrm{Mg}^{2+}$ and $\mathrm{Na}^{+}$were determined in a soil solution in a layer $0-30 \mathrm{~cm}$, in an area submitted to selective logging (6-10 trees or $34 \mathrm{~m}^{3} \mathrm{ha}$ of timber), located $80 \mathrm{~km}$ north of Manaus. The experiment was made up of three blocks, each containing one control plot and one plot submitted to selective logging. The soil in the area is very clayey Alic Yellow Latosol, with a high clay content. The samples were collected and analysed during 13 months in five treatments: control (pristine forest), centre of the clear-cut, edge of the clear-cut, edge of the remaining forest and remaining forest. Calcium, magnesium, potassium and sodium concentrations showed significant differences among the different treatment. Nitrate and ammonium ions were the less affected concentrations. In the treatments centre of the clear-cut and edge of the clear-cut, the nutrient results were, mostly, the highest values. The greatest difference occurred in the sodium concentration in the soil solution, which reached $5 \mathrm{~kg} / \mathrm{ha}$, in the centre of clear-cut of Blocks I and II, being practically twice as much as the values found on their respective control plots. The lowest concentrations of the nutrients in the soil solution on the pristine forest (control plot) and in the remaining forest confirm the efficiency of the forest in nutrient cycling. The higher concentration values of these nutrients in the centre of the clearcut, might be possibly due to the removal of trees, availability of easily decomposable materials like dead roots and accumulated litter.
\end{abstract}

\section{KEYWORDS}

forest management, nutrient cycling, forest ecosystem, central Amazonia.

${ }^{1}$ Parte da tese de doutorado apresentada ao Programa de Pós-Graduação, área de Ciências da Engenharia Ambiental, da Escola de Engenharia de São Carlos da Universidade de São Paulo.

${ }^{2}$ Coordenação de Pesquisas em Clima e Recursos Hídricos - CPCR/INPA. Cx. Postal 478, CEP 69011-970, Manaus, AM. E-mail: savio@inpa.gov.br.

${ }^{3}$ Coordenação de Pesquisas em Ecologia - CPEC/INPA. Cx. Postal 478, CEP 69011-970, Manaus, AM. 


\section{ACTA \\ AMAZONICA}

NUTRIENTES NA SOLUÇÃO DO SOLO EM FLORESTA DE TERRA FIRME NA AMAZÔNIA CENTRAL SUBMETIDA À EXTRAÇÃO SELETIVA DE MADEIRA

\section{INTRODUÇÃO}

A grande maioria dos solos de terra firme da Amazônia são considerados pobres em nutrientes, ácidos e com baixa capacidade de troca de cátions (Vieira \& Santos, 1987). Solos sob floresta primária de terra firme na Amazônia Central apresentam essas características (Ferraz et al., 1998; Ferreira et al., 2001), além de uma baixa capacidade de disponibilizar água para as plantas (Ferreira et al., 2002; Ferreira et al., 2004). O clima da região, quente e úmido, favorece os processos de intemperização de rochas e a lixiviação dos metais alcalinos e alcalino terrosos; a exposição do solo por longo tempo à ação das chuvas abundantes e de temperaturas elevadas, aliada às grossas texturas do substrato geológico, permite fácil drenagem da água de percolação, tornando o intemperismo mais intenso (Schubart et al., 1984).

O ecossistema florestal, tendo o solo, a biomassa vegetal e a liteira como compartimentos, constitui um sistema aberto, que permite a troca de massa e energia com os sistemas adjacentes, de onde recebe energia, nutrientes e água (como transportador), exportando também energia (de menor qualidade), os metabólitos não utilizáveis e água. O sistema florestal é mantido por este fluxo unidirecional entrada $\rightarrow$ saída, sendo que, no seu interior, grande parte da energia é dissipada para promover uma forte circulação, a qual faz com que se reduzam as perdas, tanto de nutrientes como de compostos ricos em energia. No sistema amazônico, a dinâmica do aproveitamento dos nutrientes é mais intensa no período chuvoso, quando o aumento da umidade favorece as atividades da biota do solo no processo de mineralizar a matéria orgânica acumulada durante o período de baixa precipitação. A estrutura macroscópica da floresta de terra firme está caracterizada por um fluxo fraco de entrada $\rightarrow$ saída, e um fluxo rápido e maciço de reciclagem (Walker \& Franken, 1983). A elevada eficiência na reciclagem de nutrientes observada nas florestas tropicais tem sido correlacionada com a sua alta diversidade biológica; e a reciclagem de nutrientes se contrapõe à lixiviação dos solos, pois representa um mecanismo de conservação de nutrientes no ecossistema, promovendo, ao mesmo tempo, a produtividade biológica e o bom estado nutricional das plantas (Schubart et al., 1984). A exuberância da floresta de terra firme é garantida por um mecanismo particular de disponibilidade e retenção de nutrientes essenciais à sua manutenção, ao lado da existência das condições básicas de calor e umidade (Franken et al., 1985). A ciclagem de nutrientes em florestas envolve um conjunto complexo de mecanismos de realimentação direta $\mathrm{e}$ indireta entre o solo e a vegetação.

$\mathrm{Na}$ água de chuva, que possivelmente corresponda à principal entrada de nutrientes no ecossistema florestal, existem dados de fluxos de íons na Reserva Florestal Adolpho Ducke, próximo de Manaus: cloreto $(13,6)$, sódio $(8,4)$, amônio $(6,60)$, potássio $(2,40)$ e fosfato $(0,10)\left(\mathrm{em} \mathrm{kg} \mathrm{ha}^{-1} \cdot \mathrm{ano}^{-1}\right)$ (Franken et al., 1985). Após percolar o dossel (precipitação interna), as concentrações de nutrientes $\left(\mathrm{kg}\right.$ ha $\left.^{-1} \cdot \mathrm{ano}^{-1}\right)$ são aumentadas para: cloretos $(29,9)$, potássio $(22,1)$, sódio $(11,10)$, amônio $(7,4)$ e fosfato $(0,27)$.
Resultados de nutrientes da água de escoamento superficial, que corresponde ao fluxo de saída ou perdas do sistema, revelam a pobreza dos solos de floresta de terra firme da bacia de drenagem do rio Negro, norte de Manaus. Franken et al. ( 1985) registraram valores de $\left(\mathrm{kg} \cdot \mathrm{ha}^{-1} \cdot \mathrm{ano}^{-1}\right)$ : cloreto $(3,94)$, amônio $(0,39)$, sódio $(0,75)$, potássio $(0,75)$, e fosfato $(0,003)$, na água de escoamento superficial de uma bacia hidrográfica, denominada Bacia Modelo. Schubart et al. (1984) também verificaram que a água da bacia do igarapé Barro Branco (água de drenagem) apresentava concentrações de nutrientes mais baixas do que a água da chuva e da precipitação interna, cujas entradas foram $\left(\mathrm{kg} \cdot \mathrm{ha}^{-1}\right.$.ano $\left.{ }^{-1}\right)$ : cloreto $(4,2)$, sódio $(0,9)$, potássio $(0,4)$, amônio $(0,2)$ e fósforo $(0,008)$. Isto confirma que boa parte dos nutrientes que entraram na floresta, são retidas pela mesma.

$\mathrm{Na}$ floresta de terra firme da Amazônia central, a maior produção de liteira fina se dá no período menos chuvoso, de junho a outubro, enquanto que a maior parte da decomposição ocorre durante a estação chuvosa (Luizão \& Schubart, 1987). As folhas, que representam $70 \%$ do total da liteira, são de rápida decomposição. A liteira fina produzida cada ano $\left(8,25 \mathrm{t} . \mathrm{ha}^{-1}\right)$, proporciona uma entrada de $3880 \mathrm{~kg}$ de carbono, $151 \mathrm{~kg}$ de nitrogênio, $3 \mathrm{~kg}$ de fósforo, $16 \mathrm{~kg}$ de enxofre, $15 \mathrm{~kg}$ de potássio, $37 \mathrm{~kg}$ de cálcio, $14 \mathrm{~kg}$ de magnésio e $9 \mathrm{~kg}$ de sódio, para o solo de uma floresta de platô sobre Latossolo Amarelo na região de Manaus (Luizão, 1989). Além destes elementos químicos geralmente considerados como nutrientes para as plantas, a floresta cicla uma quantidade significativa de outros elementos da liteira, nutrientes ou não, principalmente de silício e de alumínio, mostrando, então, uma forte relação entre a atividade biológica e a composição mineral dos solos da floresta de terra firme (Lucas et al., 1993).

O solo de terra firme (especificamente o Latossolo Amarelo) sob floresta primária de terra firme, devido a sua pobreza em nutrientes, bem como sua baixa capacidade de troca catiônica, atua apenas promovendo uma resistência a lixiviação dos nutrientes, suficiente para que os mesmos sejam eficientemente assimilados pela vegetação. No solo, a fração líquida é denominada de solução do solo, e existindo uma constante e complexa interação entre a fração sólida (reservatório de íons) e a fração líquida; quando a planta retira íons da solução do solo, sua concentração pode variar com o tempo de maneira diferente para cada nutriente e cada condição ambiental especial e por isso, a sua determinação é difícil e apenas valores médios e aproximados podem ser obtidos (Reichardt, 1996).

Considerando que a ciclagem de nutrientes, praticamente fechada, assegura a manutenção da floresta de terra firme, a remoção de árvores e a substituição de floresta por pastagens ou outras atividades agrícolas leva à diminuição de nutrientes do compartimento biomassa, transferindo-os temporariamente ao solo. Na Amazônia central, uma comparação de parcelas de floresta intacta com outras submetidas ao desmatamento e queima da vegetação, revelou que as concentrações da maioria dos íons que foram analisados, durante período chuvoso, na superfície do solo $(0-20 \mathrm{~cm})$, foram maiores sob floresta 


\section{ACTA \\ AMAZONICA}

NUTRIENTES NA SOLUÇÃO DO SOLO EM FLORESTA DE TERRA FIRME NA AMAZÔNIA CENTRAL SUBMETIDA À EXTRAÇÃO SELETIVA DE MADEIRA queimada do que sob floresta natural; porém, durante e após a estação seca seguinte e o posterior período chuvoso, foram maiores para todos os íons estudados na floresta natural (Picollo et al., 1994). Esse comportamento foi atribuído à deterioração da estrutura do solo da floresta que sofreu queima e à entrada contínua da liteira para o solo da floresta intacta.

Assim, nos trópicos, o padrão de ciclagem de nutrientes depende de várias adaptações e interações biológicas, inclusive mutualísticas entre microorganismos e plantas, que propiciam a conservação de nutrientes; a remoção desta bem-organizada estrutura biótica implica na perda de nutrientes por lixiviação sob condições de altas temperaturas e chuvas intensas. Com o objetivo de verificar se intervenções humanas menos drásticas, como a extração seletiva de madeira (E.S.M.), causa alterações nas concentrações de nitrato, amônio, potássio, cálcio, magnésio e sódio na solução do solo, o presente estudo foi conduzido em uma área de floresta de terra firme na Amazônia central submetida ao corte seletivo, que produziu diferentes níveis de dano à floresta: floresta remanescente, borda de floresta, borda de clareira e centro de clareira.

\section{MATERIAL E MÉTODOS}

Desde a década de 1980, o Instituto Nacional de Pesquisas da Amazônia - INPA, vem desenvolvendo experimentos com manejo florestal, visando a produção sustentável de madeira. Em 1993, o projeto "BIONTE" - Biomassa e Nutrientes na Floresta Tropical Úmida, que foi um projeto interdisciplinar financiado pelo DFID (Department for International Development), do Reino Unido, realizou um experimento com corte seletivo da floresta, com o intuito de estudar os efeitos ecológicos da extração seletiva de madeira e definir estratégias de corte seletivo sustentável de árvores.

Descrição do local do experimento. O experimento foi realizado na Estação Experimental de Manejo Florestal do INPA (no $\mathrm{km} 23 \mathrm{da}$ estrada vicinal ZF-2), cerca de $80 \mathrm{~km}$ ao Norte de Manaus (coordenadas geográficas: $02^{\circ} 37^{\prime}$ a $02^{\circ} 38^{\prime}$ de latitude Sul e 6009' a 60011' de longitude Oeste). A vegetação da área corresponde à Floresta Densa de Terra Firme Amazônica, com uma composição florística bastante heterogênea (Jardim \& Hosokawa, 1987). Na área deste estudo foram registradas 324 espécies de árvores, distribuídas em 173 gêneros e 57 famílias
(Jardim \& Hosokawa, 1986/87). Guillaumet (1987) distinguiu quatro estratos verticais: árvores acima de $15 \mathrm{~m}$ de altura, árvores de 12-15 m, árvores pequenas e arbustos de 7-12 $\mathrm{m}$ e arbustos até $7 \mathrm{~m}$.

O solo dos platôs da região corresponde ao Latossolo Amarelo, álico, textura muito argilosa, muito ácido, com alto teor de alumínio e baixa capacidade de troca catiônica (CTC) (Chauvel, 1982). A Tabela 1 apresenta características químicas do solo da área deste estudo (Ferreira et al. 2001). A formação geológica que predomina na área é Alter do Chão, do Cretáceo superior (Ranzani, 1980).

De acordo com a classificação climática de Köppen, o padrão característico local é do tipo "Afi”, designativo de clima equatorial quente e úmido, com chuvas abundantes e bem distribuídas ao longo do ano, sendo a temperatura média do mês mais frio sempre superior a $18{ }^{\circ} \mathrm{C}$ e possuindo características de isotermia, ou seja, com amplitude térmica média anual (média do mês mais quente menos a média do mês mais frio) inferior a $3{ }^{\circ} \mathrm{C}$; há uma curta estação seca, onde o menor índice pluviométrico (agosto) apresenta precipitação inferior a 100 $\mathrm{mm}$ (Figura 1) e com chuvas mensais que ultrapassam $290 \mathrm{~mm}$ na época chuvosa (Figura 1). Na Figura 2 os resultados médios de chuva obtidos na mesma época e local deste experimento, com intervalos entre as medidas, na maioria semanais, foi registrada uma precipitação acima de $200 \mathrm{~mm}$ entre os dias $1 \mathrm{e}$

Precipitação e umidade relativa do ar

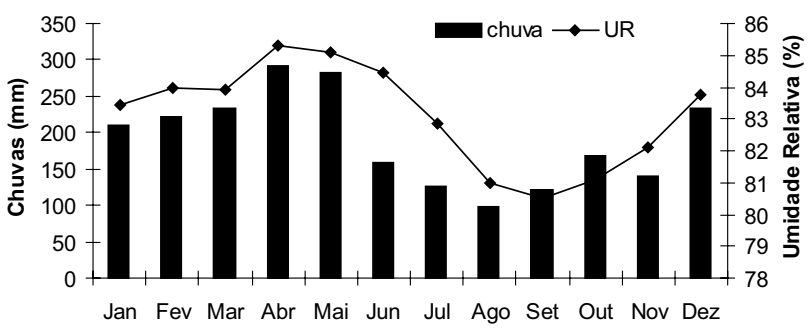

Figura 1 - Médias mensais da precipitação total e da umidade relativa do ar na estação climatológica localizada na estrada ZF. 2, km 14, no período de 1981 a 1990 (Fonte: banco de dados da CPCR/INPA).

Tabela 1 - Valores de pH, matéria orgânica do solo (MOS), P assimilável, K, Ca, Mg e Al trocáveis nas camadas de solo até 60 cm de profundidade. (Fonte: Ferreira et al., 2001).

\begin{tabular}{|c|c|c|c|c|c|c|c|c|}
\hline Prof. (cm) & $\mathrm{pH}\left(\mathrm{H}_{2} \mathrm{O}\right)$ & $\mathrm{pH}(\mathrm{KCl})$ & MOS & $\mathbf{P}$ & $\mathrm{K}$ & $\mathrm{Ca}$ & $\mathrm{Mg}$ & $\mathrm{Al}$ \\
\hline & & & g dm-3 & ------ & ------- & $\mathrm{mg} d \mathrm{dm}-3$ & ------- & ------- \\
\hline $0-10$ & 4,20 & 3,90 & 4,24 & 0,87 & 35 & 4 & 14 & 71 \\
\hline $10-20$ & 4,35 & 3,98 & 2,82 & 0,60 & 20 & 28 & 12 & 80 \\
\hline $20-30$ & 4,33 & 4,00 & 2,04 & 0,43 & 13 & 27 & 10 & 44 \\
\hline $30-40$ & 4,43 & 4,09 & 1,88 & 0,50 & 13 & 19 & 10 & 41 \\
\hline $40-60$ & 4,51 & 4,14 & 2,23 & 0,33 & 12 & 17 & 11 & 30 \\
\hline
\end{tabular}




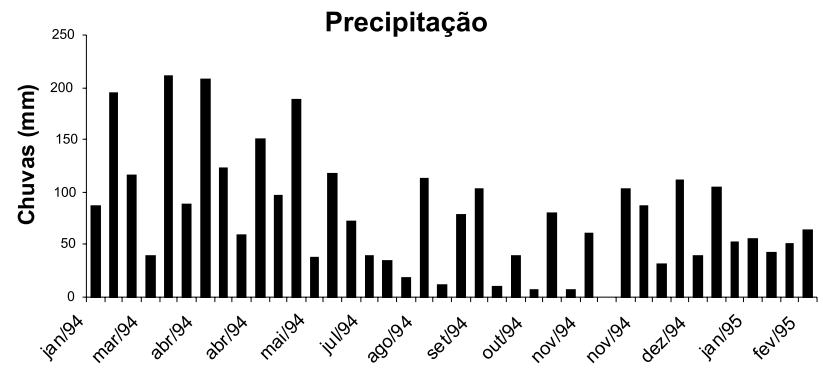

Figura 2 - Médias de precipitação (mm de chuva) no local do experimento, no período do estudo (intervalo entre as medidas na maioria semanais).

9 de março/1994. No entanto, pode-se observar a existência de uma evidente sazonalidade no clima, com os meses mais secos entre junho e novembro, seguidos de um período bastante úmido entre os meses de dezembro e maio (Uvo et al., 1988).

Delineamento experimental e tratamentos. Foi utilizado o delineamento em blocos casualisados com três repetições. Cada bloco (I, II e IV) foi dividido em seis parcelas de 4 ha cada (parcelas de 1 a 6) (Figura 3). (O bloco III, que constava no delineamento original, nunca chegou a ser manejado, por apresentar solos e topografia distintos dos outros três). Do total de 18 parcelas (de $200 \times 200 \mathrm{~m}$ ), foram investigadas três parcelas controle e três que sofreram extração seletiva de madeira (34,3 $\mathrm{m}^{3}$ ha $^{-1}$ de madeira, em média, ou 6-10 árvores ha ${ }^{-1}$ extraídas com DAP(diâmetro à altura do peito) $>55 \mathrm{~cm}$ ). $\mathrm{O}$ corte ocorreu em meados de setembro de 1993, com a retirada de árvores das espécies com potencial madeireiro, as chamadas "Espécies Listadas" (Higuchi et al., 1991). As árvores foram cortadas com motosserra e retiradas do local por um trator Cartepillar D6, produzindo cinco classes de distúrbios: trilha do trator (TT), centro de clareira (CC), borda de clareira com a floresta remanescente $(\mathrm{BC})$, borda de floresta remanescente com a clareira (BFR) e floresta remanescente (FR), que corresponde a fragmento de floresta dentro da parcela e que tem borda com clareira (Biot et al., 1997). Parcelas controle, que não sofreram extração seletiva, foram incluídas como o sexto tratamento.

Solução do solo. Em cada parcela controle foram instaladas duas baterias de extratores de solução do solo, nas profundidades de 10, 20 e $30 \mathrm{~cm}$, em locais escolhidos ao acaso no hectare central da parcela, ou seja entre os 50 e 150 m. Nas parcelas manejadas, foram instaladas baterias de extratores de solução do solo, para as três profundidades já citadas, em quatro classes de distúrbios: centro de clareira, borda de clareira com a floresta remanescente, borda da floresta remanescente com a clareira e floresta remanescente. Próximo às baterias de extratores, foram instalados tensiômetros para as medidas dos potenciais mátricos, que foram empregados nos cálculos de umidade do solo, utilizando as curvas de retenção de água no solo, conforme descrito em Ferreira et al. (2002 e 2004). As coletas foram semanais e iniciadas em fevereiro

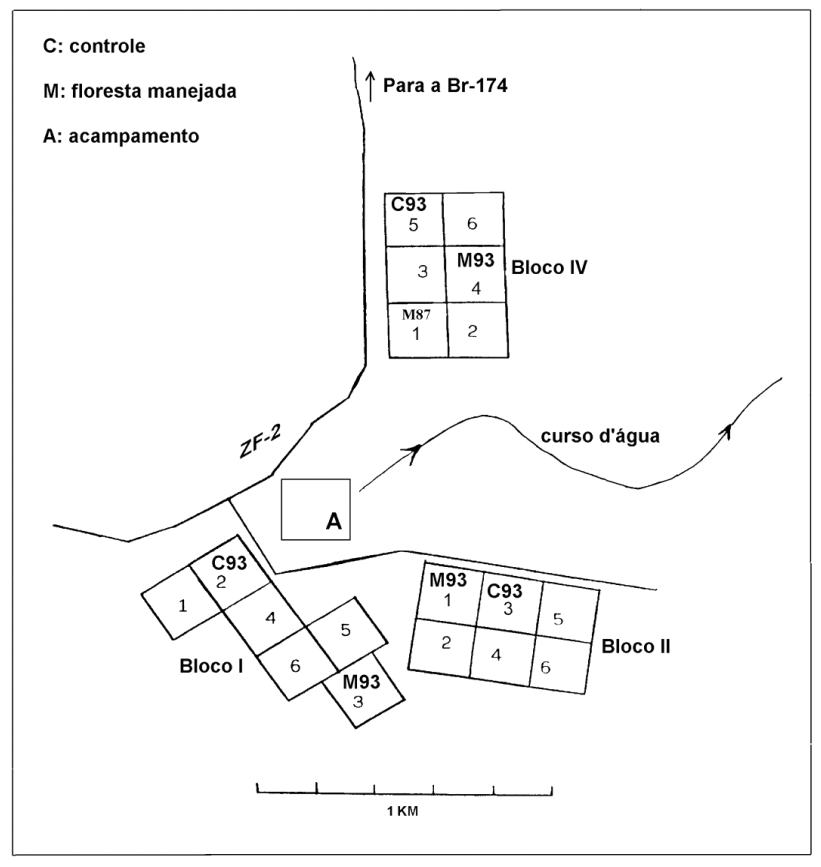

Figura 3 - Localização dos blocos I, II e IV, cada um dividido em parcelas 1 a 6, na Estação Experimental de Manejo Florestal ZF-2.

de 1994 (cinco meses após a extração de madeira), prosseguindo até fevereiro de 1995 (17 meses após a extração).

\section{Análises químicas da solução do solo}

Nitrato. Foi utilizada a técnica na qual o nitrato é reduzido a nitrito, utilizando uma coluna de cádmio; depois, foi analisado pelo sistema de fluxo contínuo (Zagatto et al., 1981).

Amônio. As amostras foram analisadas utilizando o fenol e solução de hipoclorito de sódio para formar azul de indofenol; a reação é então catalisada pelo nitroprussiato de sódio (Mackereth et al., 1978).

Potássio. Foi determinado por espectrofotometria de chama, num aparelho MICRONAL, modelo B262.

Cálcio e magnésio. As amostras foram analisadas por espectrofometria de absorção atômica, num aparelho PERKIN ELMER, modelo 1100B.

Sódio. Foi determinado por espectrofotometria de chama, num aparelho MICRONAL, modelo B262.

As quantidades dos nutrientes na solução do solo foram determinadas multiplicando-se a umidade volumétrica média do solo das três profundidades superficiais $(10,20$ e $40 \mathrm{~cm})$ pela concentração média das três profundidades $(10,20$ e 30 $\mathrm{cm}$ ), para cada nutriente, aplicada para a camada de solo de 0$30 \mathrm{~cm}$, e daí extrapolada para $1 \mathrm{ha}$. Reichardt (1996) sugeriu a seguinte equação para determinar o total de nutrientes dentro de um perfil de solo: 


\section{ACTA AMAZONICA}

NUTRIENTES NA SOLUÇÃO DO SOLO EM FLORESTA DE TERRA FIRME NA AMAZÔNIA CENTRAL SUBMETIDA À EXTRAÇÃO SELETIVA DE MADEIRA

$$
A S_{L}=\int_{0}^{L}(\theta C) d z
$$

Onde $A S_{L}$ é o armazenamento de soluto, $q$ a umidade do solo, $C$ a concentração desse soluto e $d z$ o incremento da profundidade. No presente trabalho, os cálculos foram realizados considerando tanto a concentração como a umidade, constantes em todo o perfil da camada estudada, representados por seus valores médios $(\bar{C}$ e $\bar{\theta})$; feito isto, a equação (1) pode ser integrada apenas em relação ao incremento da profundidade, dando como resultado a seguinte equação

$$
A S_{L}=\bar{\theta} \cdot \bar{C} \cdot L
$$

onde, conforme visto acima, $\bar{\theta}$ é a umidade média, $\bar{C}$ a concentração média de cada nutriente e $L$ a camada de solo, no caso, $30 \mathrm{~cm}$.

\section{Análise estatística dos dados}

Foram realizadas análises de variância com o objetivo de comparar as médias de cada nutrientes entre os tratamentos, as quais mostraram diferenças significativas. Em seguida, foram comparadas entre si as médias das quantidades dos nutrientes dos tratamentos controle, centro de clareira (CC), borda de clareira com a floresta $(\mathrm{BC})$, borda de floresta remanescente com a clareira (BFR) e floresta remanescente (FR), usando-se o teste de Tukey. Para aplicação dos testes, as médias foram agrupadas em três períodos climáticos distintos (período chuvoso: fevereiro a junho/94; período seco: julho a novembro/ 94; e transição seco-chuvoso: dezembro/94 a fevereiro/95).

\section{RESULTADOS E DISCUSSÃO}

A composição química da solução do solo apresentou diferenças significativas entre os tratamentos, principalmente para as bases $\mathrm{Ca}^{2+}, \mathrm{Mg}^{2+} \mathrm{e} \mathrm{K}^{+}$. Nas coletas semanais, o íon nitrato apresentou a quantidade mais elevada $\left(2,67 \mathrm{~kg} \mathrm{ha}^{-1}\right)$, em janeiro/94 (época chuvosa), no centro de clareira (Figura 4). Quando as médias foram agrupadas por períodos (Tabela 2), a média mais elevada (2,60 $\left.\mathrm{kg} \mathrm{ha}^{-1}\right)$ foi registrada no período seco, também no centro de clareira. Porém, as médias de nitrato na solução do solo, para os três períodos climáticos, não apresentaram diferenças significativas entre os tratamentos centro de clareira e controle ( $\mathrm{p}>0,05)$.

O valor médio mais elevado do íon amônio $\left(1,33 \mathrm{~kg} \mathrm{ha}^{-1}\right)$, foi registrado na borda de clareira, na transição do período seco para o chuvoso. No período chuvoso, os valores variaram entre 0,41 e 0,47 $\mathrm{kg} \mathrm{ha}^{-1}$ (Tabela 2).

As quantidades de cálcio na solução do solo (Tabela 2) diferiram significativamente entre os tratamentos nos três períodos: no período chuvoso o valor mais baixo, $1,98 \mathrm{~kg} \mathrm{ha}$ ${ }^{1}$, foi registrado no controle e o mais elevado, $4,51 \mathrm{~kg} \mathrm{ha}^{-1}$, na borda de clareira; no período seco, o valor mais baixo, $1,89 \mathrm{~kg}$ $\mathrm{ha}^{-1}$, também ocorreu no controle e o mais elevado, $3,91 \mathrm{~kg}$ $\mathrm{ha}^{-1}$, foi registrado no centro de clareira.

Os tratamentos mostraram diferença significativa com relação ao magnésio (Tabela 2). O controle, a floresta remanescente e a borda da floresta remanescente foram os tratamentos que apresentaram as médias mais baixas em todos os períodos do ano. A média mais baixa $\left(0,42 \mathrm{~kg} \mathrm{ha}^{-1}\right)$, foi registrada no controle, no período seco, enquanto que as médias mais elevadas foram registradas no centro de clareira $\left(2,27 \mathrm{~kg} \mathrm{ha}^{-1}\right)$ e na borda de clareira $\left(1,62 \mathrm{~kg} \mathrm{ha}^{-1}\right)$, no período chuvoso.

O sódio foi o íon encontrado em maiores quantidades na solução do solo, principalmente nos dois últimos períodos do ano. Os valores mais elevados foram registrados no período seco, com valor médio máximo de $6,49 \mathrm{~kg} \mathrm{ha}^{-1}$ (centro de clareira do bloco IV) e as quantidades no centro de clareira foram sempre mais elevadas do que no controle (Figura 5). As quantidades de potássio apresentaram diferenças significativas entre os tratamentos nos dois primeiros períodos do ano,

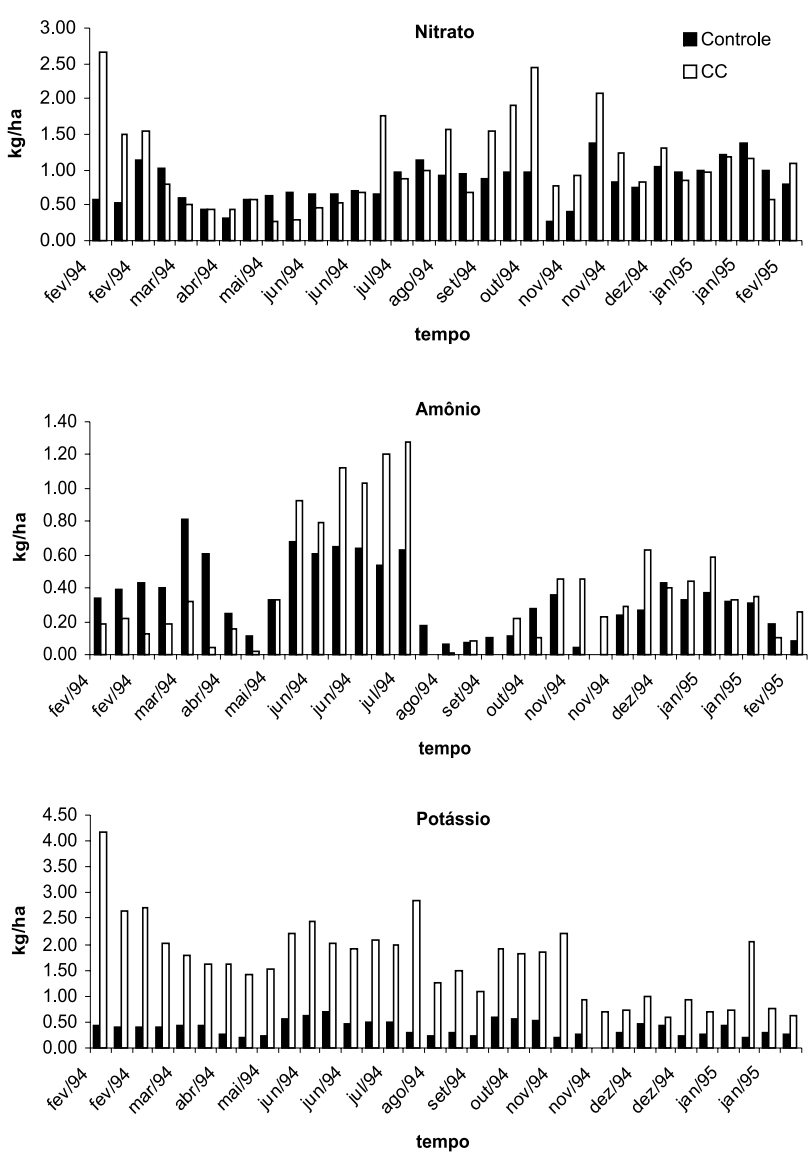

Figura 4 - Teores $\left(\mathrm{kg} \mathrm{ha}^{-1}\right)$ de nitrato, amônio e potássio na solução do solo, até a profundidade de $30 \mathrm{~cm}$, nos tratamentos: controles e centro de clareira (CC). 
Tabela 2 - Teores $\left(\mathrm{kg} \mathrm{ha}^{-1}\right)$ de nitrato, amônio, potássio, cálcio, magnésio e sódio na solução do solo até a profundidade de 30 $\mathrm{cm}$, nos tratamentos: controles, centro de clareira (CC), borda de clareira (BC), borda de floresta remanescente (BFR), e floresta remanescente (FR) considerando três períodos climáticos.

\begin{tabular}{|c|c|c|c|}
\hline \multirow[b]{2}{*}{ Tratamentos } & \multicolumn{3}{|c|}{$\mathrm{NO}_{3}-$} \\
\hline & $\begin{array}{l}\text { Período } \\
\text { chuvoso }\end{array}$ & $\begin{array}{l}\text { Período } \\
\text { seco }\end{array}$ & $\begin{array}{l}\text { Transição } \\
\text { seco- } \\
\text { chuvoso }\end{array}$ \\
\hline Controle & $0,66 a$ & $0,84 a$ & $1,03 a b$ \\
\hline $\mathrm{CC}$ & $0,83 a$ & $2,60 a$ & $1,01 a b$ \\
\hline $\mathrm{BC}$ & $0,17 \mathrm{~b}$ & $0,75 a$ & $0,89 a b$ \\
\hline BFR & $0,06 \mathrm{~b}$ & $0,30 a$ & $1,61 b$ \\
\hline \multirow[t]{2}{*}{ FR } & $0,06 \mathrm{~b}$ & $0,30 \mathrm{a}$ & $0,48 a$ \\
\hline & \multicolumn{3}{|c|}{$\mathrm{NH}_{4}^{+}$} \\
\hline Controle & $0,47 a$ & $0,24 a$ & $0,30 a$ \\
\hline $\mathrm{CC}$ & $0,46 a$ & $0,43 a$ & $0,71 a$ \\
\hline$B C$ & $0,41 a$ & $0,64 a$ & $1,33 a$ \\
\hline BFR & $0,45 a$ & $0,66 a$ & $0,94 a$ \\
\hline \multirow[t]{2}{*}{$\underline{F R}$} & $0,41 \mathrm{a}$ & $0,33 a$ & $0,57 a$ \\
\hline & \multicolumn{3}{|c|}{$\mathrm{K}^{+}$} \\
\hline Controle & $0,42 a$ & $0,38 a$ & $0,33 a$ \\
\hline $\mathrm{CC}$ & $2,15 c$ & $1,65 c$ & $0,96 a b$ \\
\hline $\mathrm{BC}$ & $1,18 b$ & $0,86 \mathrm{~b}$ & $1,01 a b$ \\
\hline BFR & $0,70 a$ & $0,57 a b$ & $1,79 b$ \\
\hline \multirow[t]{2}{*}{$\underline{F R}$} & $0,70 a$ & $0,44 a b$ & $0,51 a$ \\
\hline & \multicolumn{3}{|c|}{$\mathrm{Ca}^{2+}$} \\
\hline Controle & $1,99 a$ & $1,89 a$ & $1,33 a$ \\
\hline $\mathrm{CC}$ & $4,31 b c$ & $3,91 b$ & $2,64 b$ \\
\hline $\mathrm{BC}$ & $4,51 \mathrm{c}$ & $2,99 b$ & $2,40 a b$ \\
\hline BFR & $2,60 a$ & $2,57 a b$ & $2,65 b$ \\
\hline \multirow[t]{2}{*}{$\underline{\text { FR }}$} & 3,15ab & 2,95ab & 2,11ab \\
\hline & \multicolumn{3}{|c|}{$\mathrm{Mg}^{2+}$} \\
\hline Controle & $0,47 a$ & $0,42 a$ & $0,45 a$ \\
\hline CC & $2,27 c$ & $1,19 c$ & $1,15 b$ \\
\hline $\mathrm{BC}$ & $1,62 b c$ & $0,98 \mathrm{~b}$ & $1,15 b$ \\
\hline BFR & $0,71 a$ & $0,57 a$ & $0,75 a$ \\
\hline \multirow[t]{2}{*}{$\underline{F R}$} & $0,89 \mathrm{ab}$ & $0,76 a b$ & $0,63 a$ \\
\hline & \multicolumn{3}{|c|}{$\mathrm{Na}^{+}$} \\
\hline Controle & $2,05 a$ & $3,23 a$ & $2,85 a$ \\
\hline $\mathrm{CC}$ & $3,73 b$ & $6,49 c$ & $4,93 b$ \\
\hline BC & $3,70 \mathrm{~b}$ & $5,24 b c$ & $5,37 \mathrm{~b}$ \\
\hline BFR & $2,70 a$ & $3,60 a b$ & $4,64 a b$ \\
\hline FR & $2,82 \mathrm{ab}$ & $3,67 a b$ & 4,35ab \\
\hline
\end{tabular}

Médias seguidas pela mesma letra não diferem entre si a $5 \%$ de probabilidade.

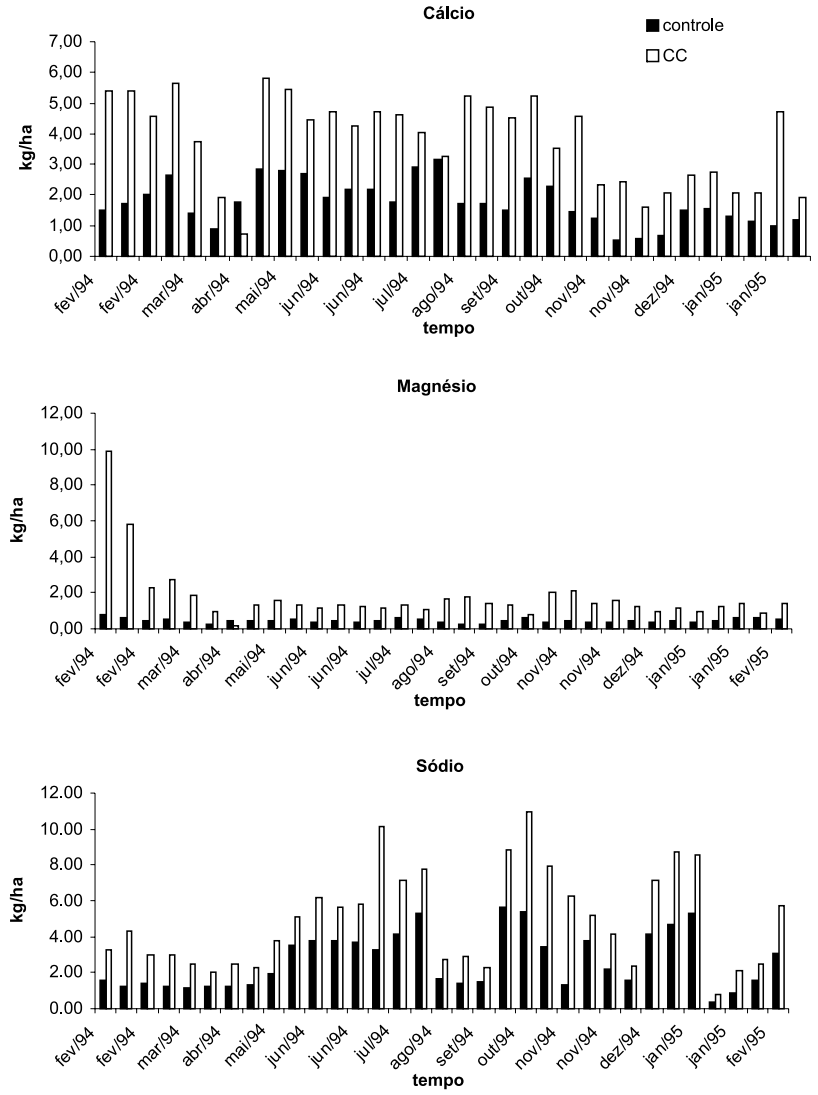

Figura 5 - Teores $\left(\mathrm{kg} \mathrm{ha}^{-1}\right)$ de cálcio, magnésio e sódio na solução do solo, até a profundidade de $30 \mathrm{~cm}$, nos tratamentos: controles e centro de clareira (CC).

sendo o valor $\left(0,38 \mathrm{~kg} \mathrm{ha}^{-1}\right)$ encontrado no controle, seguido da floresta remanescente $\left(0.44 \mathrm{~kg} \mathrm{ha}^{-1}\right)$ e borda de floresta remanescente $\left(0,57 \mathrm{~kg} \mathrm{ha}^{-1}\right)$. No período de transição não houve diferença significativa entre os tratamentos (Figura 5).

Verifica-se que os tratamentos floresta remanescente e borda de floresta remanescente tiveram o mesmo comportamento do controle, indicando que estes níveis de dano da extração de madeira não foram suficientes para causar mudanças significativas nas quantidades de cálcio. Também se observou que no centro e na borda de clareira ocorreu uma maior perda de cálcio, em relação aos outros tratamentos, ao longo do estudo. No controle, as médias de cálcio e magnésio (Tabela 2) foram as mais baixas, do que nos demais tratamentos, nos três períodos, indicando uma eficiente assimilação destes nutrientes pela vegetação.

Comparando-se os tratamentos extremos entre os que foram estudados (controle e centro de clareira), verificou-se que geralmente os nutrientes na solução do solo na camada 0 $30 \mathrm{~cm}$ foram mais elevados no centro de clareira. Isto foi mais evidente para as bases trocáveis $\left(\mathrm{K}^{+}, \mathrm{Ca}^{2+}, \mathrm{Na}^{+} \mathrm{e}\right.$, especialmente, $\mathrm{Mg}^{2+}$ ) do que para nitrato e amônio (Figuras 4 


\section{ACTA AMAZONICA}

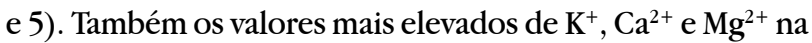
estação chuvosa, em todos os tratamentos investigados, indicam que o enriquecimento da solução do solo é proveniente da lixiviação dos produtos resultantes da mineralização da matéria orgânica, pois uma maior produção de liteira ocorre na época seca, mas a sua decomposição é acelerada na época chuvosa (Luizão \& Schubart, 1987).

No mês de fevereiro de 1994 (período chuvoso, início deste estudo), cinco meses após a extração seletiva de madeira, foram obtidos os valores mais altos de magnésio, no centro de clareira e borda de clareira. A matéria orgânica deixada pela extração de madeira libera este nutriente por meio da sua decomposição, e a falta de árvores na clareira, possivelmente seja responsável pelos valores temporariamente altos de magnésio na solução do solo, já que não há assimilação. Mas, no centro de clareira, dois meses após, ainda na época chuvosa, os teores de magnésio foram drasticamente diminuídos, provavelmente por lixiviação. Na borda da floresta remanescente e na floresta remanescente, os níveis de magnésio não sofrem grandes flutuações (Tabela 2), e no controle, praticamente nenhuma flutuação (Figura 5). Melo-Ivo et al. (1997) verificaram que, logo após o corte seletivo de árvores, ocorreu um aumento, tanto da umidade do solo quanto da concentração de nutrientes na solução do solo, devido à disponibilidade de materiais de fácil decomposição, como raízes mortas e a liteira fina acumulada. Na produção de liteira fina, de decomposição mais rápida, não incluindo galhos grossos e troncos, as folhas representam 70 $\%$ do total da liteira e sua decomposição é claramente sazonal, com valores mais elevados na estação chuvosa (Luizão \& Luizão, 1991).

Análises anteriores do solo das áreas deste estudo mostraram que, nestes solos ácidos, os teores de fósforo assimilável, potássio, cálcio, magnésio, e alumínio trocáveis são mais altos no período chuvoso do que no período seco (Ferreira et al., 2001). Os solos da Estação de Manejo Florestal da ZF-2 apresentam baixa disponibilidade de nutrientes para as plantas e podem ser classificados como distróficos, com baixa capacidade de troca efetiva de cátions; além disso, o padrão da distribuição vertical dos teores dos nutrientes trocáveis $\mathrm{K}$, Ca e Mg indica que é na camada mais superficial, onde se processa com maior intensidade a ciclagem de nutrientes e onde ocorre a maior concentração destas bases. Portanto a conservação da matéria orgânica nesses solos é extremamente importante para a manutenção da fertilidade dos solos (Ferraz et al., 1998). Os perfis do solo da floresta remanescente e do centro de clareira de um corte seletivo anterior, feito em 1987, mostraram quantidades dos elementos estudados seguindo a ordem $\mathrm{Al}>\mathrm{Ca}>\mathrm{K}>\mathrm{Mg}$, no período chuvoso, e $\mathrm{Al}>\mathrm{K}>\mathrm{Mg}$ $>\mathrm{Ca}$, no início do período seco. Há evidências de que os resíduos de madeira deixados pela extração seletiva aumentaram a concentração de nutrientes no solo, pela sua decomposição, especialmente na estação chuvosa (Ferreira $e t$ al., 2001; Yano, 2001).

No presente estudo, os nutrientes no centro de clareira apresentaram quantidades na seguinte ordem: $\mathrm{Ca}^{2+}>\mathrm{Na}^{+}>$ $\mathrm{Mg}^{2+}>\mathrm{K}^{+}>\mathrm{NO}_{3}^{-}>\mathrm{NH}_{4}^{+}$(período chuvoso) $\mathrm{Na}^{+}>\mathrm{Ca}^{2+}>$
$\mathrm{NO}_{3}^{-}>\mathrm{K}^{+}>\mathrm{Mg}^{2+}>\mathrm{NH}_{4}^{+}$(período seco) $\mathrm{e} \mathrm{Na}^{+}>\mathrm{Ca}^{2+}>$ $\mathrm{Mg}^{2+}>\mathrm{NO}_{3}^{-}>\mathrm{K}^{+}>\mathrm{NH}_{4}^{+}$(período de transição). No controle, a ordem foi: $\mathrm{Na}^{+}>\mathrm{Ca}^{2+}>\mathrm{Mg}^{2+}>\mathrm{NH}_{4}^{+}>\mathrm{NO}_{3}>\mathrm{K}^{+}$(período chuvoso); $\mathrm{Na}^{+}>\mathrm{Ca}^{2+}>\mathrm{NO}_{3}^{-}>\mathrm{Mg}^{2+}>\mathrm{K}^{+}>\mathrm{NH}_{4}^{+}$(período seco); e $\mathrm{Na}^{+}>\mathrm{Ca}^{2+}>\mathrm{NO}_{3}^{-}>\mathrm{Mg}^{2+}>\mathrm{K}^{+}>\mathrm{NH}_{4}^{+}$(período de transição). O sódio foi geralmente o íon mais abundante na solução do solo, seguido do cálcio, que foi o íon mais abundante apenas no período chuvoso (centro de clareira), indicando uma elevada taxa de liteira fina em decomposição no período, pois é o que tem a maior proporção das bases trocáveis (Luizão, 1989). As bases trocáveis, $\mathrm{Mg}^{2+} \mathrm{e} \mathrm{K}^{+}$, alternaram-se em quantidades na solução do solo e tenderam a diminuir do período chuvoso para o período de transição (seco-chuvoso), mais intensamente na clareira do que no controle. Considerando que, logo após o corte seletivo, ocorreu uma diminuição da demanda de nutrientes com a remoção de árvores e conseqüente morte de suas raízes, houve uma maior concentração temporária de nutrientes disponíveis no solo de clareiras. No centro das clareiras, o aumento da exposição do solo à entrada de água da chuva e de luz, favoreceu: (1) o estabelecimento de plântulas das espécies arbóreas pioneiras e clímax sobre o solo (Leal-Filho, 2000), que assimilam nutrientes; e (2) o transporte de nutrientes para as camadas mais profundas do solo e, assim, a sua exportação do sistema solo-planta, pelos processos de fluxo de solutos: convectivo, difusão, dispersão hidrodinâmica e o combinado destes (Hillel, 1998).

Os resultados do presente estudo concordam com os de Piccolo et al. (1994), que estudaram a composição mineral da solução do solo durante 16 meses (uma estação seca e dois períodos chuvosos) em uma floresta natural e uma submetida a desmatamento e queima da vegetação. Observaram que, no primeiro período úmido, os fluxos totais dos íons mais

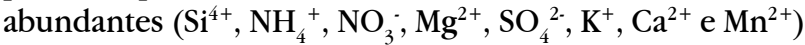
foram maiores sob floresta queimada do que sob floresta natural; porém, para os dois períodos seguintes, um seco e outro chuvoso, os fluxos de nutrientes foram mais elevados na floresta natural. A contínua entrada de liteira, que chega à superfície do solo em floresta natural, e não em áreas que sofreram derruba e queima, tem importância crítica para regular a concentração da maioria desses nutrientes na solução do solo. No presente estudo, cinco meses após o corte seletivo de árvores, os tratamentos que sofreram maiores danos, como o centro de clareira e a sua borda, também mostraram aumentos nos teores das bases trocáveis $\mathrm{K}^{+}, \mathrm{Ca}^{2+}, \mathrm{Mg}^{2+} \mathrm{e} \mathrm{Na}^{+}$, e também foi observada, a seguir, uma ligeira perda de $\mathrm{K}^{+}, \mathrm{Ca}^{2+}, \mathrm{e} \mathrm{Mg}^{2+}$. Apesar dessa perda de nutrientes nas áreas afetadas, os níveis ainda estiveram acima das áreas intactas (controle), indicando que o corte seletivo não provocou um empobrecimento na solução do solo, como ocorre em manejo com derruba e queimada da vegetação.

\section{CONCLUSÕES}

A extração seletiva de madeira causou alterações significativas nas quantidades de potássio, cálcio, magnésio e sódio, que 
foram maiores na solução do solo nos tratamentos "centro de clareira" e "borda de clareira", os mais impactados pela exploração de madeira. O sódio foi o íon mais afetado.

A diminuição gradativa dos teores de nitrato, potássio, cálcio e magnésio no centro de clareira, ao longo deste, mostraram que estes estão sendo exportados do sistema soloplanta. No entanto, como suas quantidades na solução do solo ao final do estudo ainda eram mais altas do que no controle, não houve evidências de que a extração seletiva de madeira, no nível em que foi efetuada, tenha causado uma depleção importante nos nutrientes necessários para o crescimento da floresta remanescente ou sucessão secundária natural.

\section{AGRADECIMENTOS}

Aos colegas, Pedrinho de Almeida Paiva, Jonas de Oliveira Moraes, Luiz Vilmar Souza da Silva e Walter Jorge do Nascimento Filho (INPA), pelo apoio de campo e laboratório. Também somos gratos a Sheila M. Ross ( University of Liverpool - England), Walane Maria Pereira de Mello-Ivo (CPATC/EMBRAPA), Yvan Biot (Department for International Development DFID), João Augusto Dantas de Oliveira (INPA) e Folco H. H. H. van Rij, pelas valiosas ajudas e sugestões no texto.

\section{BIBLIOGRAFIA CITADA}

Biot, Y.; Ferraz, J.; Luizão, F.; Minete, L. 1997. Levantamento de habitats após a exploração seletiva de madeira. Projeto BIONTE - Biomassa e nutrientes florestais - Relatório final. MCT/INPA, Manaus, Amazonas. p. 67-85.

Chauvel, A. 1982. Os latossolos amarelos, álicos, argilosos dentro dos ecossistemas das bacias experimentais do INPA e da região vizinha. Acta Amazonica, 12(3): 47-60.

Ferraz, J; Ohta, S; Salles, P.C. 1998. Distribuição dos solos ao longo de dois transectos em floresta primária ao Norte de Manaus (AM). In: Higuchi, N.; Campos, M.A.A.; Sampaio, P.T.B.; Santos, J. (Eds). Pesquisas Florestais para a Conservação da Floresta e Reabilitação de Áreas Degradadas da Amazônia. Instituto Nacional de Pesquisas da Amazônia. Manaus, Amazonas. p. 110-143.

Ferreira, S.J.F.; Crestana, S.; Luizão, F.J.; Miranda, S.A.F. 2001. Nutrientes no solo em floresta de terra firme cortada seletivamente na Amazônia Central. Acta Amazonica, 31(3): 381-396.

Ferreira, S.J.F.; Luizão, F.J.; Mello-Ivo, W.; Ross, S.M.; Biot, Y. 2002. Propriedades físicas do solo após extração seletiva de madeira na Amazônia central. Acta Amazonica, 32(3): 449-466.

Ferreira, S.J.F.; Luizão, F.J.; Ross, S.M.; Biot, Y: Mello-Ivo, W.M.P. 2004. Soil water storage in an upland forest after selective logging in Central Amazonia. R. Bras. Ci. Solo, 28: 59-66.

Franken, W; Leopoldo, P.R.; Bergamin Filho, H. 1985. Fluxo de nutrientes através de águas naturais em floresta de terra firme na Amazônia Central. In: Workshop on Biogeochemistry of Tropical Rain Florest: Problems for Research. Proceedings. Piracicaba, São Paulo. p. 29-37.

Guillaumet, J.L. 1987. Some structural and floristic aspects of the forest. Experientia, 43(3): 241-251.

Higuchi, N.; Vieira, G.; Minete, L.J.; Freitas, J.V.; Jardim, F.C.S. 1991. Sistema S. E. L. (Seleção de Espécies Listadas) para manejar a floresta tropical úmida de terra firme da Amazônia. In: Val, A.L.; Figlioulo, R.; Feldberg, E. (Eds). Bases Científicas para Estratégias de Preservação e Desenvolvimento da Amazônia: Vol 1. Instituto Nacional de Pesquisas da Amazônia. Manaus, Amazonas. p. 197-206.

Hillel, D. 1998. Environmental soil physics. San Diego, Academic Press. $771 \mathrm{p}$.

Jardim, F.C.S; Hosokawa, R.T. 1986/87. Estrutura da floresta equatorial úmida da Estação Experimental de Silvicultura Tropical do INPA. Acta Amazonica, 16(17): 411-508.

Leal Filho, N. 2000. Dinâmica inicial da regeneração natural de florestas exploradas na Amazônia brasileira. Tese de Doutorado, Universidade de São Paulo, São Paulo, São Paulo. 157p.

Lucas, Y; Luizão, F.J.; Chauvel, A.; Rouiller, J.; Nahon, D. 1993. The relation between biological activity of the rain forest and the mineral composition of soils. Science, 260: 521523.

Luizão, F.J.; Schubart, H.O.R. 1987. Litter production and decomposition in a terra-firme forest of Central Amazonia. Experientia, 43(3): 259-265.

Luizão, F.J. 1989. Litter production and mineral element input to the forest floor in a Central Amazonian forest. GeoJournal, 19(4): 407-417.

Luizão, R.C.C.; Luizão, F.J. 1991. Liteira e biomassa microbiana do solo no ciclo da matéria orgânica e nutrientes em terra firme na Amazônia Central. In: Val, A.L.; Figlioulo, R.; Feldberg, E. (Eds). Bases científicas para estratégias de preservação e desenvolvimento da Amazônia: fatos e perspectivas. Vol. 1. Instituto Nacional de Pesquisas da Amazônia. Manaus, Amazonas. p.65-75.

Mackereth, F.J.H.; Heron, J.; Talling, J.F. 1978. Water analysis: some revised methods for limnologists. Freshwater Biological Association Scientific Publication n. 36. 120pp.

Mello-Ivo, W.; Ferreira, S.; Biot, Y; Ross, S. 1997. Nutrientes na solução do solo após o corte seletivo de madeira em Floresta Tropical Úmida de Terra Firme ao Norte de Manaus, Brasil. Projeto BIONTE - Biomassa e nutrientes florestais Relatório final. MCT/INPA, Manaus, Amazonas. p. 173-181.

Piccolo, M.C.; Andreux, F.; Cerri, C.C. 1994. Hydrochemistry of soil solution collected with tension-free lysimeters in native and cut-and-burned tropical rain forest in Central Amazonia. Geochim. Brasil, 8(1): 51-63.

Ranzani, G. 1980. Identificação e caracterização de alguns solos da Estação Experimental de Silvicultura Tropical do INPA. Acta Amazonica, 10 (1): 7-41.

Reichardt, K. 1996. Dinâmica da matéria e da energia em ecossistemas. $2^{\mathrm{a}}$. ed., USP/ESALQ. Piracicaba, São Paulo. 513pp. 
Schubart, H.O.R.; Franken, W.; Luizão, F.J. 1984. Uma floresta sobre solos pobres. Ciência Hoje, 2(10): 26-32.

Uvo, C.R.B.; Nobre, C.A.; Citeau, J. 1988. Análise da posição da Zona de Convergência Intertropical (ZCIT) no Atlântico Equatorial e sua relação com a precipitação no Nordeste do Brasil. In: Anais do V Congresso Brasileiro de Meteorologia, 07-11 novembro. Rio de Janeiro.

Vieira, L. S.; Santos, P.C.T.C. 1987. Amazônia seus solos e outros recursos naturais. Ed. Agronômica Ceres. São Paulo. 416 pp.

Walker, I.; Franken, W. 1983. Ecossistemas frágeis: a floresta da terra firme da Amazônia Central. Ciencia Interamericana, 23: 9-21.
Yano, C.Y. 2001. Efeitos da liteira fina sobre a disponibilidade de nutrientes e o crescimento de plântulas em áreas de extração seletiva de madeira na Amazônia Central. Dissertação de Mestrado, Instituto Nacional de Pesquisas da Amazônia/Universidade Federal do Amazonas, Manaus, Amazonas. 71pp.

Zagatto, E.A.G.; Jacintho, A.O.; Reis, B.F.; Krug, F.J.; Bergamin Filho, H.; Pessenda, L.C.R.; Mortatti, J.; Giné, M.F. 1981. Manual de análises de plantas e águas empregando sistema de injeção em fluxo. CENA/USP. Piracicaba, São Paulo. 45pp.

RECEBIDO EM 29/03/2005
ACEITO EM 19/12/2005 
